\title{
Difficulties in semantically congruent translation of verbally and symbolically represented algebraic statements
}

\author{
Encarnación Castro ${ }^{1}$ (D) María C. Cañadas ${ }^{1}$ (D) $\cdot$ Marta Molina $^{2}$ (D) . \\ Susana Rodríguez-Domingo ${ }^{1}$
}

Accepted: 12 July 2021 / Published online: 17 November 2021

(c) The Author(s) 2021, corrected publication 2022

\begin{abstract}
This paper describes the difficulties faced by a group of middle school students (13- to 15-year-olds) attempting to translate algebraic statements written in verbal language into symbolic language and vice versa. The data used were drawn from their replies to a written quiz and semi-structured interviews. In the former, students were confronted with a series of algebraic statements and asked to choose the sole translation, of four proposed for each, that was semantically congruent with the original. The results show that most of the errors detected were due to arithmetic issues, especially around the distinction between product and exponent or sum and product in connection with the notions of perimeter and area. As a rule, the error distribution by type varied depending on the type of task involved.
\end{abstract}

Keywords Algebraic statements · Verbal representation · Representation · Algebraic symbolism · Translation

The capacity to reason about concepts represented in different systems and "switch" adeptly from one to another ("representational fluency," to use a term coined by Nathan et al. (2010)) is a key mathematical skill. Representation and inter-system relationships, particularly as concerns arithmetic and algebra, are concepts that should be mastered by students, according to the standards defined by the US Common Core State Standards Initiative (Council of Chief State School Officers and the National Governors Association Center for Best Practices, 2016). The Program for International Student Assessment (PISA), in turn, stipulates that representation is an imperative skill (OECD, 2005), associated with others, such as understanding and using different types of representations for mathematical objects, phenomena, and situations (coding, de-coding, interpreting, distinguishing among types); understanding and using the relationships between different representations of the same concept, including their relative soundness and limitations; and choosing representation systems and translating from one to another (Niss \& Højgaard,

María C. Cañadas

mconsu@ugr.es

1 Departamento de Didáctica de La Matemática, Universidad de Granada, Facultad de Ciencias de la Educación. Campus de la Cartuja, s/n, 18071 Granada, Spain

2 Universidad de Salamanca, Salamanca, Spain 
2011; Rico, 2006). Both the US and PISA standards stress the importance of the ability to reason with and translate to and from the various representations of a given mathematical idea.

Representation systems are likewise acknowledged to be mediators in the conveyance of thoughts and mathematical communication (Kilpatrick et al., 2001), as well as powerful intellectual tools:

...algebraic reasoning in its many forms, and the use of algebraic representations

such as graphs, tables, spreadsheets and traditional formulas, are among the most powerful intellectual tools that our civilization has developed. Without some form of symbolic algebra, there could be no higher mathematics and no quantitative science, hence no technology and modern life as we know them. (Kaput, 1998, pp. 3-4)

Given the importance of representational fluency in algebra and specifically in translation between verbal and symbolic representation, this skill is explored in depth in the present study. Duval (2006) contended that understanding the nature of students' skills and their translation difficulties calls for engaging them in different tasks requiring translation along with mechanisms for observing the procedures they use to perform such tasks. Further to those principles, a research project was designed in which middle school students were asked to perform three tasks: (a) to build non-contextualized algebraic statements, (b) to build algebraic statements in a given context, and (c) to identify semantically congruent translations of contextualized algebraic statements. This article reports on the findings gleaned from the third. The focus is on the difficulties students encountered when translating from verbal to algebraic symbolism, and vice versa. More specifically, the description of the errors committed in the process provides insight into students' difficulties in identifying semantically congruent translations of algebraic statements. The discussion of those findings is preceded by a description, under the headings Representation and Translation, of the underlying conceptual premises and the results of earlier studies.

\section{Representation}

Representation is requisite to knowledge management and communication, in mathematical contexts in particular. As the image of a thing absent but evoked (Duval, 1999), representation is not equivalent to what it represents. To quote Rico (2006), "to represent is to substitute, to make visible something absent and, hence, this fact confirms its absence" (p. 6). Similarly, Duval (2006) notes that "the mathematical objects must never be confused with the semiotic representations that are used" (p. 107).

A distinction is generally drawn between internal representation, as in the abstraction or internalization of mathematical ideas or cognitive schemes (the way a person conceives of unknowns) and external representation, including the signs, digits, or similar things used to symbolize, describe, codify, or represent an idea for the intents and purposes of communication (Goldin \& Shteingold, 2001; Rico, 2009).

The text below refers to the latter type of representation. In mathematics, representation must be systemic. Researchers have differentiated sign (Kieran \& Filloy, 1989), notation (Kaput, 1992) and semiotic systems (Duval, 1993). Although arising from different theories, all three systems use symbols, graphics, and notations governed by rules and convention. Any given mathematical notion can normally be expressed with more than one type of representation. Each type refers to some part of the notion, and all complement 
one another. "This need of various registers of representation gives rise to several questions that are important in order to understand the real conditions of learning mathematics" (Duval, 1999, p. 7).

\subsection{Representation in classroom algebra}

This study addresses symbolic and verbal representation of algebraic statements in writing and translation from one to another. In mathematics, verbal communication is based on everyday oral or written language (Cañadas \& Figueiras, 2011). The former, with its deployment of pauses, gestures, and tones of voice as support for meaning, is more complex (Freudenthal, 1983). In written language, some of those clues are conveyed by punctuation. "Two times five, plus eight" is not equivalent to "two, times five plus eight," for instance.

Symbolic representation or algebraic symbolism is characteristic of algebra, where inter-quantity relationships are represented with conventional symbols (Kieran, 1996). With its use of numerals, letters, and signs typical of arithmetic and algebra symbolic notation, that type of representation can potentially represent algebraic ideas separately from their initial context (Arcavi, 1994).

Algebraic notation is characterized by high compaction power. This aspect of the language makes it possible to move fluently through layers of abstraction and compress complex mathematical thoughts into efficient symbol strings. At the same time, however, these characteristics make symbolic writing very opaque for learners. The substantial ambiguity inherent in symbols, while advantageous for experts, is difficult for novices (Drouhard \& Teppo, 2004, p. 240).

\section{Translation}

Translating from one representation system to another consists in transforming information coded in one type of mathematical representation (the source) to another (the target) (Bossé et al., 2011; Janvier, 1987). A translation, or conversion to use Duval's term (1999, 2006), entails changing the representation system without changing the mathematical object. In that process, the constructs or ideas that are expressed in the source are successfully reformulated in the target system (Bossé, et al., 2014). Any such translation must be semantically congruent; i.e., the mathematical meaning in the former must be accurately expressed in the latter (Lesh et al., 1987). Consequently, translation converts not the representation per se, but rather the ideas or constructs represented (Adu-Gyamfi et al., 2012).

\subsection{Difficulties posed by translation}

Earlier research has addressed the difficulties encountered in translating between representation systems. Jupri and Drijvers (2016) identified one of the five major categories of difficulties in algebra to be translating verbally worded problems into mathematical symbols.

Research has shown that to successfully translate from verbal language to algebraic symbols and vice versa, students must understand the variables, their mutually dependent relationships described in words, and the syntax embodied in symbolic representation (Kaput et al., 1985). Other obstacles that may spawn errors in symbolic representation include weak or non-existent language skills (Kar, 2016) or the ensuing difficulties 
in explaining the relationship between symbolism and verbal representation (Capraro \& Joffrion, 2006).

Adu-Gyamfi et al. (2012) designed a "translation-verification model" to explain the procedures applied by students to translate from one mathematical representation to another. Their model envisages three types of verification: (a) implementation, (b) attribute, and (c) equivalence. For implementation verification, "in any given translation, a student/translator must map elements of the source representations onto elements of the target representations. Such an activity can be performed procedurally with little or no attention given to the embodiments characterized in either representation" (p. 161). "Attribute verification provides confirmation that an authentication activity performed on the source and target representations for the purpose of establishing that the defining ideas or attributes of the source representation are encoded in the target representation has been properly performed" (p. 162). Through equivalence verification, "the student/translator has to actively check that all defining attributes or properties of both source and target representations have been faithfully translated in terms of the preservation of mathematical meaning" (p. 163).

Those three verification categories can be associated with three types of student errors when translating: (a) implementation, (b) interpretation, and (c) preservation. The first error type "usually happens when a step in an algorithm is incorrectly executed" (p. 163). Interpretation error is incurred when "the student incorrectly ascribes, characterizes, or exemplifies attributes or properties of either the source or target representation" (p. 163). In preservation error, the student "correctly maintains semantic congruence between the source and target representations for self-identified attributes or properties but fails to confirm that other relevant attributes or properties are also correctly translated" (p. 164).

The error classification proposed by Molina et al. (2017), deemed to be a precedent instrumental to this study, groups errors in symbolic $\Leftrightarrow$ verbal translation under the following three main headings:

- Statement sufficiency-related errors consist in the absence of necessary or presence of unnecessary symbols or words in the translation. Its sub-categories are incomplete and superfluous.

- Arithmetic-related errors are associated with the misinterpretation of signs or operations. It includes the sub-categories absence of necessary and presence of unnecessary parentheses as well as mistaking the following pairs of operations: division-multiplication, exponentiation-multiplication, addition-multiplication, and division-exponentiation.

- Algebraic system-related errors, sub-divided into generalization, particularization, letter, and structural complexity errors.

\subsection{Translation from verbal language to algebraic symbolism $(V \Rightarrow S)$}

The reasons for the translation errors made by students in this type of translations include the use of merely syntactic procedures when translating, a limited understanding of the notion of variable and the syntactic characteristics of symbolic statements, along with the failure to understand problem wording due to syntactical complexity (Cerdán, 2010; Molina, 2014; Rodríguez-Domingo, \& Molina, 2013; Ruano et al., 2008). In connection with the third reason, Bossé, et al. (2011) contend that the presence of irrelevant, confusing, or inexplicit 
information in word problems exacerbates translation difficulties. MacGregor and Stacey (1993) reported that students use more than one cognitive procedure, translating either syntactically or semantically. In syntactic translations, students translate word for word from left to right with little regard for meaning. In semantic translation, they perceive the overall meaning of the word problem and express it symbolically. These authors observed that students found it difficult to reorganize verbal statements when transforming them into symbolic language and to recognize the precision of algebraic symbols which, as Socas (1997) noted, are much more powerful than verbal language.

\subsection{Translation from algebraic symbolism to verbal language $(S \Rightarrow V)$}

Fairly few studies have addressed the translation from symbolic representation into verbal language, and those that have were conducted, as a rule, in a problem-posing context (e.g., Cañadas et al., 2018; Fernández-Millán \& Molina, 2016; Jupri \& Drijvers, 2016; Koedinger \& Nathan, 2004). One of the conclusions reached in studies on translation to and from different representation systems in algebra is that students find semantic consistency elusive even when they understand the source and target statements (Brenner et al., 1997).

The present study explores students' ability to distinguish semantically congruent translations for a number of algebraic statements by identifying the difficulties encountered. This approach, unprecedented in the literature, is based on five assumptions. (a) A difficulty is an obstacle that may breed translation errors (Jupri \& Drijvers, 2016). (b) Verbal representation is governed by the use of everyday language with the occasional inclusion of mathematical terminology. (c) In algebraic symbolism arithmetic numerals, letters and specific arithmetic and algebraic signs are used for written representation. (d) An algebraic statement is a sentence that can be expressed with algebraic symbols, such as "the sum of two consecutive numbers is equal to a third number minus two," which in algebraic symbolism would be $x+(x+1)=y-2$. (e) A closed statement such as $x(x+1)=7 x$ differs from its open counterparts such as $x+(x+1)-4$ in that it expresses an equality.

\section{Research objective}

The study described in this article was designed to determine the difficulties faced by a group of middle school (13- to 15-year-old) students when translating between the two representation systems taught in classroom algebra, written verbal (V) and symbolic (S) language in both directions $(\mathrm{V} \Leftrightarrow \mathrm{S})$. The students were asked to choose the right translation of a given statement from one of the two representation systems into the other.

\section{Method}

The type of research conducted, the subjects comprising the sample, the data collection design and implementation, and the data analysis procedures deployed are described in the sub-sections that follow. 


\subsection{Type of research}

The choice of an ex post facto, exploratory, descriptive study (Hernández et al., 2003) was justified by the paucity of earlier research on the issue addressed, which has nonetheless been identified as relevant in the literature. Data analysis was essentially qualitative (based on subjects' justifications and explanations provided during interviews), supplemented with a quantitative element, the frequencies of students' replies in their written tasks.

\subsection{Subjects}

The sample comprised 16 s-year middle school students enrolled in a public school. Their ages ranged from 13 to 15 . The sample was intentional, based on school, student, and classroom teacher (a research team member) availability. The teacher-researcher gave the students no specific instructions about the study, delivering standard lessons as set out in the students' textbook (Colera et al., 2008). Prior to data collection, the students had worked on arithmetic (whole number division, decimal and sexagesimal numbering systems, fractions, proportionality, and percentage) and algebraic (algebraic statements, equations, and systems of equations) concepts.

\subsection{Data design and collection}

Data were collected from a written task and during one subsequent semi-structured interview with each student. The written task consisted of a multiple-choice quiz designed to be performed individually. It was divided into two parts or situations, with four algebraic statements or items each. In situation 1, the source statements were given in verbal representation to be translated into symbolic language, and in situation 2 , the converse. Students were given four possible translations for each statement, only one of which was semantically congruent with the source. They were asked to choose the option they deemed appropriate and to justify their choice.

The tasks and the kind of questions posed were similar to those proposed in the students' textbook and designed to encompass the following parameters: (a) type of structure (addition, multiplication, exponentiation), (b) type of sentence (open, closed), and (c) number of letters involved (one or two). The verbal statements proposed addressed geometric (length, area, volume) and numerical (age, numbers, and quantities of objects) contexts routinely found in the textbook (Colera et al., 2008). The incorrect options were drawn from answers given by the same group of students in a session conducted the week before, when they were asked to build non-contextualized algebraic statements (Molina et al., 2017; Rodríguez-Domingo et al., 2015). Exposing them to their own errors on the questionnaire used for data collection was a tactic aimed to make the mistaken sentences look more reasonable and induce students to analyze and compare the statements in greater depth, for they were told that only one of the choices was correct. 
The written data were collected during students' mathematics class. In that classroom session, the teacher-researcher acted as observer, confining her participation to solving practical problems or clarifying instructions. She later adopted the role of interviewer, as discussed in a later section. The tool used to collect the written data and the subsequent semi-structured interviews is described below.

\subsection{Tool for collecting written data}

Table 1 lists the four symbolic statements and the four multiple-choice answers given for each. The erroneous answers were designed to match the classification described earlier.

Table 2 lists the four verbal statements and the four multiple-choice answers for each.

Table 1 Symbolic statements, multiple choices, and associated errors

\begin{tabular}{|c|c|c|c|c|}
\hline & $\begin{array}{l}\text { Symbolic } \\
\text { statement }\end{array}$ & Choices & & Associated error \\
\hline \multirow[t]{4}{*}{ E1.1 } & \multirow[t]{4}{*}{$5+x+y$} & (a) & $\begin{array}{l}\text { Five plus my sister's age (in years) plus my age } \\
\text { (in years) plus my sister's age (in years) }\end{array}$ & SR Superfluous \\
\hline & & (b) & Five times my age and my sister's age & $\begin{array}{l}\text { AR Addition mistaken } \\
\text { for multiplication }\end{array}$ \\
\hline & & (c) & $\begin{array}{l}\text { Five plus the sum of my sister's and my ages } \\
\text { (in years) }\end{array}$ & $\checkmark$ \\
\hline & & (d) & $\begin{array}{l}\text { An odd number plus one person's age (in years) } \\
\text { plus another person's age (in years) }\end{array}$ & AS Generalization \\
\hline \multirow[t]{4}{*}{ E2.1 } & \multirow[t]{4}{*}{$x+60=5 x$} & (a) & The sum of a number plus sixty equals five & SR Incomplete \\
\hline & & (b) & $\begin{array}{l}\text { A number plus sixty equals five times that } \\
\text { number times five }\end{array}$ & SR Superfluous \\
\hline & & (c) & $\begin{array}{l}\text { When sixty is added to a number the result is } \\
\text { the same as if it were multiplied times five }\end{array}$ & $\checkmark$ \\
\hline & & (d) & $\begin{array}{l}\text { A number plus sixty equals five times another } \\
\text { number }\end{array}$ & AS letters \\
\hline \multirow[t]{4}{*}{ E3.1 } & \multirow[t]{4}{*}{$x^{2}-y^{2}=9$} & (a) & $\begin{array}{l}\text { The area of the floor of my square room minus } \\
\text { the area of the floor of your square room }\end{array}$ & SR Incomplete \\
\hline & & (b) & $\begin{array}{l}\text { The difference between the areas of the floors } \\
\text { of two square rooms is an odd number }\end{array}$ & AS Generalization \\
\hline & & (c) & $\begin{array}{l}\text { The perimeter of the floor of my square room } \\
\text { minus the perimeter of the floor of your } \\
\text { square room equals nine }\end{array}$ & $\begin{array}{l}\text { AR Perimeter mistaken } \\
\text { for area }\end{array}$ \\
\hline & & (d) & $\begin{array}{l}\text { The difference between the areas of two square } \\
\text { rooms is nine }\end{array}$ & $\checkmark$ \\
\hline \multirow[t]{4}{*}{ E4.1 } & \multirow[t]{4}{*}{$x^{3}$} & (a) & The area of a cube & $\begin{array}{l}\text { AR Volume mistaken } \\
\text { for area }\end{array}$ \\
\hline & & (b) & Triple the side of a cube & $\begin{array}{l}\text { AR Exponent mistaken } \\
\text { for product }\end{array}$ \\
\hline & & (c) & The volume of a cube & $\checkmark$ \\
\hline & & (d) & Three raised to three & AS letter \\
\hline
\end{tabular}

$\checkmark$ correct answer, $S R$ sufficiency-related, $A R$ arithmetic-related, $A S$ algebraic symbolism-related. 
Table 2 Variable statements, multiple choices, and associated error

\begin{tabular}{|c|c|c|c|c|}
\hline & Verbal statement & Choices & & Error \\
\hline \multirow[t]{4}{*}{ E1.2 } & \multirow{4}{*}{$\begin{array}{l}\text { The perimeter of a rectangular } \\
\text { garden, that is six meters longer } \\
\text { than wide, is ninety-two meters }\end{array}$} & (a) & $x+x+(x+6)+(x+6)=92$ & $\checkmark$ \\
\hline & & (b) & $x+(x+6)=92$ & SR Incomplete \\
\hline & & (c) & $2 x \cdot 2(x+6)=92$ & $\begin{array}{l}\text { AR Product and } \\
\text { addition }\end{array}$ \\
\hline & & (d) & $x+x+y+y=92$ & SR Incomplete \\
\hline \multirow[t]{4}{*}{ E2.2 } & \multirow{4}{*}{$\begin{array}{l}\text { Double Jesús's age (in years) } \\
\text { plus one fourth of Ines's age } \\
\text { (in years) }\end{array}$} & (a) & $4+\frac{x}{4}$ & SR Incomplete \\
\hline & & (b) & $2 x+\frac{x}{4}$ & AS letters \\
\hline & & (c) & $2 x+\frac{y}{4}$ & $\checkmark$ \\
\hline & & (d) & $2 x+\frac{4}{y}$ & $\begin{array}{l}\mathrm{AR} \\
\text { Fraction terms }\end{array}$ \\
\hline \multirow[t]{4}{*}{ E3.2 } & \multirow[t]{4}{*}{$\begin{array}{l}\text { Between them, two cars have } \\
\text { eight wheels }\end{array}$} & (a) & $x^{2}=8$ & $\begin{array}{l}\text { AR Product and } \\
\text { exponent }\end{array}$ \\
\hline & & (b) & $2 x=8 y$ & SR Superfluous \\
\hline & & (c) & $x=8$ & SR Incomplete \\
\hline & & (d) & $2 x=8$ & $\checkmark$ \\
\hline \multirow[t]{4}{*}{$\mathrm{E} 4.2$} & \multirow{4}{*}{$\begin{array}{l}\text { The area of the bottom of a } \\
\text { square swimming pool times } \\
\text { the depth of the pool }\end{array}$} & (a) & $x^{2}$ & SR Incomplete \\
\hline & & (b) & $x^{2} \cdot y$ & $\checkmark$ \\
\hline & & (c) & $2 x \cdot y$ & $\begin{array}{l}\text { AR Product and } \\
\text { exponent }\end{array}$ \\
\hline & & (d) & $2 x^{2} \cdot y$ & SR Superfluous \\
\hline
\end{tabular}

$\checkmark$ correct answer, $S R$ sufficiency-related, $A R$ arithmetic-related.

\subsection{Interviews}

The week after the written task session, the teacher/researcher conducted individual semi-structured interviews with all the students to enquire about their wrong answers and their unintelligible or non-existent explanations. As the interviewer gave them no explanations or instructions whatsoever during the interview, merely asking for explanations for their answers, the interviews involved no direct instruction. The students did not work with the statements during the week lapsing between the written task and the interview, nor did they know which was the correct choice for each item. Although some students changed their initial answer to some items during the interview, those second answers were excluded from the analysis, for the interviews sought merely to determine the difficulties detected through the errors observed in the written tasks.

\subsection{Data analysis}

The data were classified under the error categories proposed by Molina et al. (2017) and analyzed in terms of the Adu-Gyamfi et al. (2012) translation verification model, which is valid for exploring contexts where algebraic or geometric notions can be represented in more than one way. Implementation verification was assumed to be equivalent to decision-making in the present study.

The number of correct and incorrect choices under each item in each situation was tallied. The number of times each choice was selected was also recorded. Some of the explanations for the choices are also given below in the form of fragments drawn from the interviews. 


\section{Results}

The number of correct and incorrect choices for the items in the two situations is given in Table 3.

All students answered all the items in the two situations. The prevalence of correct and incorrect answers in situations 1 and 2 was reversed. In the $\mathrm{S} \Rightarrow \mathrm{V}$ direction, the number of correct answers ranged from 3 to 9 and incorrect answers from 7 to 13 . In the $\mathrm{V} \Rightarrow \mathrm{S}$ direction, the number of correct answers ranged from 7 to 12 and that of incorrect answers from 4 to 9 .

The best result in situation $1(\mathrm{~S} \Rightarrow \mathrm{V})$ was observed for statement E2.1 $(x+60=5 x)$, where the number of correct choices was highest and incorrect choices lowest. The statement in that item involved addition and multiplication in a closed, numerical context. In contrast, item E4.1 $\left(x^{3}\right)$ elicited the smallest number of correct and largest number of incorrect answers. The context of that exponential statement was open and geometric. Both statements contained a single letter.

In situation $2(\mathrm{~V} \Rightarrow \mathrm{S}), \mathrm{E} 1.2$, involving addition in a closed geometric context and a single letter ("the perimeter of a rectangular garden, which is six meters longer than wide, is ninety-two meters"), exhibited the smallest number of correct and the largest of incorrect answers. In the other three statements, the numbers of correct and incorrect choices were more evenly distributed.

A comparison of the findings for the two situations revealed that when students were given a symbolic statement for which they had to choose a verbal translation (situation 1), the number of correct answers was slightly over half the number of incorrect answers. The opposite was observed when they were given a verbal statement for which a symbolic translation had to be chosen. Moreover, the distribution of correct and incorrect answers was more uniform in situation 2 than in situation 1, where it was more scattered.

The inference is that in this multiple-choice task, the students found it more difficult to identify the right translation of a symbolic to a verbal representation than of a verbal to a symbolic representation.

Situation $1(\mathrm{~S} \Rightarrow \mathrm{V})$ comprised two open $\left(\mathrm{E} 1.1(5+x+y+x)\right.$ and E4.1 $\left.\left(x^{2}\right)\right]$ and two closed $\left(\mathrm{E} 2.1(x+60=5)\right.$ and E3.1 $\left.\left(x^{2}-y^{2}=9\right)\right)$ statements. There were fewer correct than incorrect student answers to the open statements, as well as to one of the closed statements. In contrast, in situation 2, more correct than incorrect answers were provided in the two open (E2.2 and E4.2) and one of the two closed (E2.1 and E2.3) statements, with the contrary observed for only one of the closed statements. Furthermore, from a joint analysis of data from the two situations, more incorrect responses were given to open statements in situation 1, whereas in situation 2, such statements were interpreted correctly more often than incorrectly.

Table 3 Number of correct/incorrect choices in the two situations

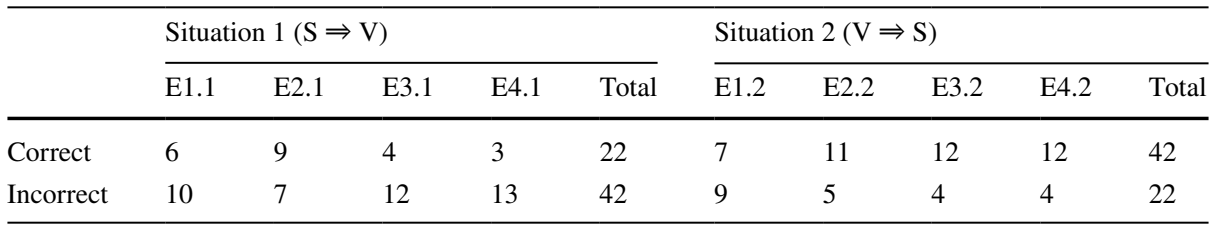


Table 4 Number of correct responses in situations 1 and 2

\begin{tabular}{llll}
\hline $\begin{array}{l}\text { No. of items } \\
\text { answered correctly }\end{array}$ & \multicolumn{2}{l}{ No. of students } \\
\cline { 2 - 4 } & $\begin{array}{l}\text { Situation } 1(\mathrm{~S} \\
\Rightarrow \mathrm{V})\end{array}$ & $\begin{array}{l}\text { Situation 2 }(\mathrm{V} \\
\Rightarrow \mathrm{S})\end{array}$ & Both $(\mathrm{S} \Leftrightarrow \mathrm{V})$ \\
\hline 4 & 1 & 5 & 1 \\
3 & 2 & 2 & 0 \\
2 & 2 & 7 & 0 \\
1 & 7 & 2 & 1 \\
0 & 4 & 0 & 0 \\
\hline
\end{tabular}

The number of correct answers recorded for each situation separately and to both jointly is given in Table 4.

Table 4 shows that only one student answered the four questions in situation 1 correctly and four answered all four items incorrectly. Just one student correctly answered the eight questions in situations 1 and 2 combined, whereas 13 answered more of the situation 2 than the situation 1 items correctly. The number of errors by situation and type of error is listed in Table 5.

In situation $1(\mathrm{~S} \Rightarrow \mathrm{V})$, most of the implementation errors were arithmetic-related (AR), with very few sufficiency-related (SR) and only one associated with algebraic symbolism (AS). In situation $2(\mathrm{~V} \Rightarrow \mathrm{S})$, the same number of errors was attributable to sufficiency as to arithmetic and fewer to algebraic symbolism. Overall, errors were most frequently related to arithmetic, in particular the mistaken choice of type of operation, more than likely due to the failure to distinguish between concepts such as perimeter and area of a plane figure, which constitute interpretation errors. The next frequent type of errors was attributable to sufficiency, while those associated with algebraic symbolism were of scant significance.

The number of times each option was chosen by the students is given in Table 6, where the correct answer bears an asterisk.

According to the data in Table 6 , in situation $1(\mathrm{~S} \Rightarrow \mathrm{V})$, the correct answer was the one most frequently chosen only in additive-multiplicative, closed statement E2.1 $(x+60=5 x)$, which involved one letter and an arithmetic context. In E1.1 $(5+x+y$ : additive, open, two letters, and numerical context), option (d), which entailed a generalization error, was the one most frequently chosen. One student's reasoning for choosing that answer was indicative of preservation error: "Because the symbolic statement gives us 5 which would be the odd number, plus $x$ which would be an age that we don't know, plus $y$ that would be the other age that we don't know."

In the interviews, when students were prompted to reflect on the suitability of choice (c) by asking them why they chose (d) as the translation for E1.1, most argued that although (c) correctly translated the source statement, generalizing the symbolic statement should also

Table 5 Number of errors by situation, item, and type

\begin{tabular}{|c|c|c|c|c|c|c|c|c|c|c|}
\hline \multirow[t]{2}{*}{ Error type } & \multicolumn{5}{|c|}{ Situation $1(S \Rightarrow V)$} & \multicolumn{5}{|c|}{ Situation $2(\mathrm{~V} \Rightarrow \mathrm{S})$} \\
\hline & E1.1 & E2.1 & E3.1 & $\mathrm{E} 4.1$ & Total & $\mathrm{E} 1.2$ & $\mathrm{E} 2.2$ & E3.2 & $\mathrm{E} 4.2$ & Total \\
\hline Sufficiency-related & 1 & 7 & - & - & 8 & 6 & - & 1 & 2 & 9 \\
\hline Arithmetic-related & 9 & - & 11 & 13 & 33 & 3 & 1 & 3 & 2 & 9 \\
\hline Algebraic symbolism-related & - & - & 1 & - & 1 & - & 4 & - & - & 4 \\
\hline Total & 10 & 7 & 12 & 13 & 42 & 9 & 5 & 4 & 4 & 22 \\
\hline
\end{tabular}


Table 6 Number of times each multiple-choice option was chosen

\begin{tabular}{|c|c|c|c|c|c|c|c|c|}
\hline \multirow[t]{2}{*}{ Choice } & \multicolumn{4}{|c|}{ Situation $1(\mathrm{~S} \Rightarrow \mathrm{V})$} & \multicolumn{4}{|c|}{ Situation $2(\mathrm{~V} \Rightarrow \mathrm{S})$} \\
\hline & E1.1 & E2.1 & E3.1 & $\mathrm{E} 4.1$ & E2.1 & E2.2 & E3.2 & $\mathrm{E} 4.2$ \\
\hline (a) & 0 & 1 & 0 & 5 & $7 *$ & 0 & 3 & 1 \\
\hline (b) & 1 & 2 & 1 & 8 & 4 & 4 & 0 & $12 *$ \\
\hline (c) & $6^{*}$ & $9 *$ & 11 & $3 *$ & 3 & $11 *$ & 1 & 2 \\
\hline
\end{tabular}

*Correct choice.

be deemed to be correct. Their justification adopted the form of "they're both right" (S16), "well it's the same, I could use five or any odd number" (S12), "they're the same to me, because an odd number would be five..." (S15), likewise constituting preservation error.

In contrast, in additive, exponential, closed statement E3.1, $\left(x^{2}-y^{2}=9\right)$, with two letters and a geometric context, only one student chose the incorrect option involving generalization (b). In that statement the most frequently chosen of the three wrong answers was option (c), where perimeter was mistaken for area.

Although the students failed to clearly justify their choices in writing, in the interviews, most, knowing that they were dealing with a square figure, mistook one geometric concept for the other (interpretation error), as shown in the following fragment from an interview with S06:

I: When we have a square, to calculate the perimeter you have to add all four sides; to calculate the area, you multiply two sides. Here, then, what am I talking about?

S06: The area, then it's not right.

I: Could you tell me which one is?

S06: Of these, which is right? d.

I: Why?

S06: Because the area, like you said, is multiplying the sides. And here it's squared because we multiply two sides. ' $X$ ' squared is ' $x$ ' times ' $x$ ', ' $y$ ' squared or ' $y$ ' times ' $y$ '. Well, you subtract and the answer is nine.

For statement E4.1 (exponentiation, open, one letter, geometric context), five students chose option (a), in which volume was mistaken for area. The most frequently chosen incorrect answer was (b), in which exponent was mistaken for product. A fragment of the interview with S07, who made that mistake, follows:

I: For statement four in situation one, you chose b, which says 'triple the side of a cube' as the right option. And you explained that was "because the side would be " $x$ " and the triple is "x cubed". What is the triple of a number?

S07: Multiplying it times three.

I: And multiplying times three is the same as raising it to the third power?

S07: No because it would be... it would be times three and the other would be multiplying the same number times itself three times.

I: Is the explanation right or wrong then?

S07: It's wrong. Because it's not the triple of ' $x$ '.

In contrast to situation 1 , in situation $2(\mathrm{~V} \Rightarrow \mathrm{S})$ (Table 6$)$, the correct answers outnumbered the incorrect choices. In additive, closed statement E1.2 ("the perimeter of a 
rectangular garden, which is six meters longer than wide, is ninety-two meters") with one letter and a geometric context, students incorrectly chose translations that were missing information (b), mistook addition for multiplication (c), or misinterpreted the relationship described in the item (d). The written explanations did not help clarify students' choices (e.g., S05: "because it doesn't say what it is"; S08: "because the perimeter is a perimeter the sum of all its sides and it begins with $x$ ”).

In additive-multiplicative, open statement E2.2 (“double Jesús's age in years plus onequarter of Inés's age in years") with two letters and a numerical context, one student incorrectly chose an answer that mistook the denominator for the numerator of a fraction (d) and four marked option (b), in which two unknowns, each involving a different person, were combined. That mistake was made because the students focused only on the word "years." One student justified his choice by explaining: "Because it's double Jesus's age in years plus one-fourth Ines's in years."

During the interviews, some students acknowledged that since the situation referred to the ages of different people, they should be represented with different letters and that consequently the symbolic statement in (c) best translated the verbal statement, which was in fact the only one that was semantically congruent with the source.

In multiplicative, closed statement E3.2 ("the number of wheels on two cars is eight"), one student chose option (c) and three (a), errors respectively associated with missing information (coefficient) and mistaking the exponent for the product. This last choice was justified by one student who contended that "the number of wheels on two cars is $x$ squared and the answer is eight."

In multiplicative-exponential statement E4.2 ("the area of the bottom of a square swimming pool times the depth of the pool") with two letters and a geometric context, one student left out information given in the wording (a), one added information (c), and two (S06 and S07) mistook the exponent for the product, explaining that "side times side is $2 x$." The latter two, with the researcher's help during the interviews, calculated the area of a square figure and acknowledged that it correctly translated the source wording.

Generally speaking, as shown in the fragments reproduced above, during the interviews the students changed the incorrect for the correct choice when prompted to reflect on their answer.

\section{Discussion}

This paper reports on the difficulties experienced by students in identifying the semantic consistency of verbally and symbolically represented algebraic statements. The findings, based on their replies to a questionnaire consisting in multiple-choice questions and their own oral and written justifications for their answers, supplement the results of earlier studies analyzing student translations of algebraic statements to and from those two systems of representation. Here, the more extensive data called for by Duval (2006) are furnished in an attempt to define students' skills and difficulties in connection with translating classroom algebra statements.

In this study, the findings, which given the small number of subjects and sessions can be neither generalized nor viewed incautiously, corroborated an observation reported by Brenner et al. (1997), Fernández-Millán and Molina (2016), and Cañadas et al. (2018): students found it difficult to preserve semantic and syntactic consistency in inter-representational translations. Such difficulties induced incorrect choices in the context of what the 
Adu-Gyamfi et al. (2012) model defines as interpretation verification. The students often chose translations that failed to express all the ideas and relationships in the source, lacked necessary or contained superfluous information, or changed the relationship between terms in the statement. The choice of incomplete translations is an indication that letters (Küchemann, 1981) or relevant information is being ignored.

Asking students to identify semantically congruent translations in multiple-choice items, the approach adopted here and not found elsewhere in the literature, revealed that they were less prone to choose the right verbal target when the source was a symbolic statement than the other way around, a finding recorded for both open and closed statements. That differed from the results observed in earlier studies when the same students were asked to translate non-contextualized algebraic statements themselves (Molina et al., 2017; Rodríguez-Domingo et al., 2015). In those studies, subjects were less successful when translating from verbal to symbolic statements.

Such discrepancies between the two datasets provide support for the premise that the difficulty was due not to the instruction delivered but to other factors. In multiple-choice exercises where students were to identify the correct translation from symbolic to verbal language, the findings suggest that the precision of the former may have constituted an obstacle. In other words, students failed to realize that the algebraic relationships defined in symbolic statements must be converted to very precise verbal expressions. In one example observed here, some students failed to distinguish between "5" and "an odd number," which they found equally valid as translations of the original. That finding was interpreted to denote students' scant perception of the precision of symbolic statements or awareness of the need for such precision in mathematical language. Students tended to read the verbal translations proposed for a given symbolic statement too summarily. Including their own erroneous interpretations among the choices offered and telling them only one option was correct did not seem to help students detect the differences in precision between expressions or suffice to indicate where arithmetic operations were confounded. That obstacle is associated with characteristics of mathematical expression such as precision and phrasing brevity and density (Forman et al., 1998; Schleppegrell, 2007) that should be addressed in the classroom.

Most of the errors observed in this study in both directions of translation were arithmetic-related and would be classifiable as interpretation error (Adu-Gyamfi et al., 2012). Writing $2 x$ rather than $x^{2}$, for instance, attests to confusion between additive and multiplicative structures. The frequent mistaking of product for exponent and vice versa may be attributable to the much greater stress placed on multiplication than exponentiation in Spanish secondary school textbooks. Arithmetic operations were also associated with geometric concepts (perimeter, area, or volume). Arithmetic-related errors (mistaking one operation for another) revealed the failure to distinguish between geometric concepts such as perimeter and area of a plane, or area and volume of a three-dimensional, figure. Such errors stem from interference from new learning in mathematics (MacGregor \& Stacey, 1997) or perhaps from a tendency identified by Kaput (1998):

When we deal with formalisms, whether traditional algebraic ones or those more exotic, our attention is on the symbols and syntactical rules for manipulating those formalisms rather than on what they might stand for, with much of their power arising from internally consistent, referent-free operations. (p. 7)

When prompted to ponder those ideas during the interview, many students acknowledged and corrected their error, remembering forgotten knowledge. That would constitute equivalence verification, with students maintaining the attributes perceived in the source 
representation in the option chosen. The subjects who persevered in their error provide examples of preservation error as defined in the Adu-Gyamfi et al. (2012) model.

Translation is therefore impacted by elements unrelated to the task per se. The present findings suggest that the adverse effects of the presence of irrelevant, confusing or inexplicit information on translation (Bossé et al., 2011) may be compounded by elements not fully understood or partially forgotten, which constitute an added difficulty for students when undertaking that task.

The error distribution observed here varied substantially from earlier findings when students were asked to translate the expressions themselves rather than choose one from a list of options (Molina et al., 2017). In the data collected for this study, statement sufficiency-related errors, i.e., misidentification of the mathematical concepts involved, were much more common than those associated with algebraic symbolism.

Statement openness was observed to have opposite effects in the two situations: in situation 1 more open statements fostered more incorrect responses whereas in situation 2 closed statements accounted for the larger number of wrong answers. Another feature of statements that had a bearing on difficulties to accurate translation was the order of the terms. Students experienced less difficulty in statements reading from left to right, the order preferred by persons whose algebraic thinking is procedural (Crowley et al., 1994).

\section{Conclusions}

This study aimed to establish the difficulties encountered by 13 - to 15 -year-old students when translating between symbolic and verbal representation of algebraic statements. The data used were student errors on a multiple-choice questionnaire consisting in identifying the single correct target language version of a statement in the source language from among four options. Students were observed to translate from verbal to symbolic language more successfully than vice versa. That was contrary to the findings of an earlier study when they were asked to translate statements themselves, where higher performance was recorded in the opposite direction (Molina et al., 2017; Rodríguez-Domingo et al., 2015). The errors in both directions primarily involved arithmetic, specifically the incorrect identification of the operation required, along with a tendency to ignore known or unknown quantities in the statements. Student perception of the algebraic symbolism in these statements played only a minor role in these errors.

Translation, whether from verbal to symbolic statements or vice versa, is clearly not a mechanical process, as discussed in the introductory paragraphs of this paper. On the contrary, it calls for semantic understanding of the verbal language and knowledge of algebraic symbols, in addition to a sound command of the mathematical ideas contained in the statements. Teachers should bear that in mind when working with the translation between representation systems, for students have been shown to perform best in the type of translations which are routinely taught in the classroom (Bossé et al., 2011). Inasmuch as algebraic symbolism describes numerical relationships more synoptically than verbal representation (Usiskin, 1999), the use of (opaque) formalisms is an area that should be addressed in the classroom. As Kaput (1998, p. 9) noted, "Most fruitful use of symbols involves alternating between action on symbols without reference to what they might stand for and then interpreting the results semantically." More specifically, classroom work should explicitly stress the importance of precision in algebraic contexts, particularly as concerns algebraic symbolism, given the highly synthetic nature of such representation and the lack of support for 
its interpretation such as present in oral language in the form of intonation and descriptive context. If these recommendations go unheeded, students will be scantly able to flexibly use different representation systems to work with and communicate mathematical ideas, to the detriment of the mathematical competence known as "representation" (Rico, 2006). This paper shows that students find it difficult to perform the type of translation studied and that the difficulties observed may vary with the nature of the task at hand. The issues facing students when choosing a translation for a given representation as identified here are believed to hamper their fluent use of mathematical representation. Classroom work should therefore systematically include a variety of tasks involving translation to and from the various systems to enable them to improve their performance in that respect.

Funding Open Access funding provided thanks to the CRUE-CSIC agreement with Springer Nature. The research described in this paper was conducted with funding provided by Spain's National Research Agency (Spanish initials, AEI) and the European Regional Development Fund (ERDF) under projects EDU201675771-P and PID2020-113601GB-I00. Funding for open access charge: Universidad de Granada / CBUA.

Open Access This article is licensed under a Creative Commons Attribution 4.0 International License, which permits use, sharing, adaptation, distribution and reproduction in any medium or format, as long as you give appropriate credit to the original author(s) and the source, provide a link to the Creative Commons licence, and indicate if changes were made. The images or other third party material in this article are included in the article's Creative Commons licence, unless indicated otherwise in a credit line to the material. If material is not included in the article's Creative Commons licence and your intended use is not permitted by statutory regulation or exceeds the permitted use, you will need to obtain permission directly from the copyright holder. To view a copy of this licence, visit http://creativecommons.org/licenses/by/4.0/.

\section{References}

Adu-Gyamfi, K., Stiff, L. V., \& Bossé, M. J. (2012). Lost in translation: Examining translation errors associated with mathematical representations. School Science and Mathematics, 112(3), 159-170.

Arcavi, A. (1994). Symbol sense: Informal sense-making in formal mathematics. For the Learning of Mathematics, 14(3), 24-35.

Bossé, M. J., Adu-Gyamfi, K., \& Cheetham, M. R. (2011). Assessing the difficulty of mathematical translations: Synthesizing the literature and novel findings. International Electronic Journal of Mathematics Education, 6(3), 113-133.

Bossé, M. J., Adu-Gyamfi, K., \& Chandler, K. (2014). Students' differentiated translation processes. International Journal for Mathematics Teaching \& Learning. Consultado el 17/01/2019 de http://www. cimt.org.uk/journal/

Brenner, M. E., Mayer, R. E., Moseley, B., Brar, T., Duran, R., Reed, B. S., \& Webb, D. (1997). Learning by understanding: The role of multiple representations in learning algebra. American Educational Research Journal, 34(4), 663-689.

Cañadas, M. C., \& Figueiras, L. (2011). Uso de representaciones y generalización de la regla del producto [Use of representations and generalisation of the multiplication principle]. Infancia y Aprendizaje, 34(4), 409-425.

Cañadas, M. C., Molina, M., \& del Río, A. (2018). Meanings given to algebraic symbolism in problem posing. Educational Studies in Mathematics, 98(1), 19-37.

Capraro, M. M., \& Joffrion, H. (2006). Algebraic equations: Can middle-school students meaningfully translate from words to mathematical symbols? Reading Psychology, 27(2-3), 147-164.

Cerdán, F. (2010). Las igualdades incorrectas producidas en el proceso de traducción algebraico: Un catálogo de errores [Incorrect equalities developed in the algebraic translation process: A catalog of errors]. PNA, 4(3), 99-110.

Colera, J., Martínez, M., Gaztelu, I., \& Oliveira, M. J. (2008). Matemáticas $4^{\circ}$ educación secundaria, opción A. Anaya. 
Council of Chief State School Officers (CCSSO) and the National Governors Association Center for Best Practices (NGA Center) (2016). Available at http://www.corestandards.org/Math/?

Crowley, L., Thomas, M., \& Tall, D. (1994). Algebra, symbols, and translation of meaning. In Proceedings of the 18th Conference of the International Group for the Psychology of Mathematics Education (V.2, pp. 240-247).

Drouhard, J. P., \& Teppo, A. R. (2004). Symbols and language. In The future of the teaching and learning of algebra: The 12th ICMI study (pp. 225-264). Springer.

Duval, R. (1993). Registros de representación semiótica y funcionamiento cognitivo del pensamiento [Register of semiotic representation and cognitive functioning of thinking]. Annales De Didactique Et De Sciencies Cognitives, 5, 37-65.

Duval, R. (1999). Representation, vision and visualization: Cognitive functions in mathematical thinking. Basic issues for learning. In F. Hitt \& M. Santos (Eds.), Proceedings of the 21st Annual Meeting of the North American Chapter of the International Group for the Psychology of Mathematics Education (pp. 3-26). PME-NA.

Duval, R. (2006). A cognitive analysis of problems of comprehension in a learning of mathematics. Educational Studies in Mathematics, 61(1-2), 103-131.

Fernández-Millán, E. F., \& Molina, M. (2016). Indagación en el conocimiento conceptual del simbolismo algebraico de estudiantes de secundaria mediante la invención de problemas [Inquiry into secondary students' conceptual knowledge of algebraic symbolism through problem posing]. Enseñanza de las Ciencias, 34(1), 53-71.

Forman, E. A., McCormick, D. E., \& y Donato R. . (1998). Learning what counts as a mathematical explanation. Linguistics and Education, 9(4), 313-339.

Freudenthal, H. (1983). Didactical phenomenology of mathematical structures. Reidel.

Goldin, G., \& Shteingold, N. (2001). Systems of representations and the developments of mathematical concepts. In A. Couco \& F. Curcio (Eds.), The roles of representation in school mathematics (pp. 1-23). National Council of Teachers of Mathematics.

Hernández, R., Fernández, C., \& Baptista, P. (2003). Metodología de la investigación (3ª ed) [Research methodology]. Mac Graw Hill.

Janvier, C. (1987). Translation process in mathematics education. In C. Janvier (Ed.), Problems of representations in the teaching and learning of mathematics (pp. 27-31). Lawrence Erlbaum Associates.

Jupri, A., \& Drijvers, P. H. M. (2016). Student difficulties in mathematizing word problems in algebra. Eurasia Journal of Mathematics, Science and Technology Education, 12(9), 2481-2502.

Kaput, J. J. (1992). Technology and mathematics education. In D. A. Grouws (Ed.), Handbook of research on mathematics teaching and learning (pp. 515-556). Macmillan.

Kaput, J. J. (1998). Teaching and learning a new algebra with understanding. National Center for Improving Student Learning and Achievement in Mathematics and Science.

Kaput, J. J., Sims-Knight, J. E., \& y Clement, J. . (1985). Behavioral objections: A response to Wollman. Journal for Research in Mathematics Education, 16(1), 56-63.

Kar, T. (2016). Prospective middle school mathematics teachers' knowledge of linear graphs in context of problem-posing. International Electronic Journal of Elementary Education, 8(4), 643.

Kieran, C. (1996). The changing face of school algebra. In C. Alsina, J. Alvarez, B. Hodgson, C. Laborde, \& A. Pérez (Eds.), $8^{\text {th }}$ International Congress on Mathematical Education: Selected lectures (pp. 271290). S.A.E.M. Thales.

Kieran, C., \& Filloy, E. (1989). El aprendizaje del álgebra escolar desde una perspectiva psicológica [The learning of school algebra from a psychological perspective]. Enseñanza de las Ciencias, 7(3), 229-240.

Kilpatrick, J., Swafford, J., \& Findell, B. (2001). Adding it up: Helping children learn mathematics. National Academy Press.

Koedinger, K. R., \& Nathan, M. J. (2004). The real story behind story problems: Effects of representations on quantitative reasoning. The Journal of the Learning Sciences, 13(2), 129-164.

Küchemann, D. E. (1981). Algebra. In K. M. Hart, M. L. Brown, D. E. Küchemann, D. Kerslake, G. Ruddock, \& M. McCartney (Eds.), Children's understanding of mathematics: 11-16 (pp. 102-119). John Murray.

Lesh, R., Post, T., \& Behr, M. (1987). Representations and translations among representations in mathematics learning and problem solving. In C. Janvier (Ed.), Problems of representations in the teaching and learning of mathematics (pp. 33-40). Erlbaum.

MacGregor, M., \& Stacey, K. (1993). Cognitive models underlying students' formulation of simple linear equations. Journal for Research in Mathematics Education, 24(3), 217-232.

MacGregor, M., \& Stacey, K. (1997). Students' understanding of algebraic notation: 11-15. Educational Studies in Mathematics, 33(1), 1-19. 
Molina, M. (2014). Traducción del simbolismo algebraico al lenguaje verbal: Indagando en la comprensión de estudiantes de diferentes niveles educativos [Translation from algebraic symbolism to verbal language: Investigating the students' understanding in different educative levels]. Gaceta de la Real Sociedad Matemática Española, 17(3), 559-579.

Molina, M., Rodríguez-Domingo, S., Cañadas, M. C., \& Castro, E. (2017). Secondary school students' errors in the translation of algebraic statements. International Journal of Science and Mathematics Education, 15(6), 1137-1156.

Nathan, M. J., Masarik, K., Stephens, A. C., Alibali, M. W., \& Koedinger, K. R. (2010). Enhancing middle school students' representational fluency: A classroom-based study. Downloaded the 14/11/2016 from http://wcereb.ad.education.wisc.edu/docs/workingpapers/Working_Paper_No_2010_09.pdf

Niss, M., \& Højgaard, T. (Eds.) (2011). Competencies and mathematical learning. Ideas and inspiration for the development of mathematics teaching and learning in Denmark. IMFUFA.

OECD. (2005). Informe PISA 2003. Aprender para el mundo de mañana [Learning for tomorrow world]. Santillana.

Rico, L. (2006). La competencia matemática en PISA [Mathematical competence in PISA]. PNA, 1(2), $47-66$.

Rico, L. (2009). Sobre las nociones de representación y comprensión en la investigación [About the representation and comprehension notions in the research]. PNA, 4(1), 1-14.

Rodríguez-Domingo, S., \& Molina, M. (2013). De lo verbal a lo simbólico: un paso clave en el uso del álgebra como herramienta para la resolución de problemas y la modelización matemática [From verbal to symbolic: A key step in the use of algebra as a tool for problem solving and mathematical modelling]. In L. Rico, M. C. Cañadas, J. Gutiérrez, M. Molina e I. Segovia (Eds.), Investigación en Didáctica de la Matemática. Homenaje a Encarnación Castro (pp. 111-118). Comares.

Rodríguez-Domingo, S., Molina, M., Cañadas, M. C., \& Castro, E. (2015). Errores en la traducción de enunciados algebraicos entre los sistemas de representación simbólico y verbal [Errors in the translation of algebraic statements between symbolic and verbal representation systems]. PNA. Revista de Investigación en Didáctica de la Matemática, 9(4), 273-293.

Ruano, R. M., Socas, M. M., \& Palarea, M. M. (2008). Análisis y clasificación de errores cometidos por alumnos de secundaria en los procesos de sustitución formal, generalización y modelización en álgebra [Secondary students' error analysis and classification in formal substitution, generalization and modelling process in algebra]. PNA, 2(2), 61-74.

Schleppegrell, M. (2007). The linguistic challenges of mathematics teaching and learning: A research review. Reading and Writing Quarterly, 23, 139-159.

Socas, M. (1997). Dificultades, obstáculos y errores en el aprendizaje de las matemáticas en la educación secundaria [Difficulties, obstacles, and errors in the learning of mathematics in Secondary Education]. In L. Rico (Ed.), La Educación Matemática en la Enseñanza Secundaria (pp. 125-154). Horsori.

Usiskin, Z. (1999). Conceptions of school algebra and uses of variables. In B. Moses (Ed.), Algebraic thinking, grades K-12: Readings from NCTM's school-based journals and other publications (pp. 7-13). National Council of Teachers of Mathematics.

Publisher's note Springer Nature remains neutral with regard to jurisdictional claims in published maps and institutional affiliations. 